\title{
Pharmacogenetic Analysis of Genes Implicated in Rodent Models of Antidepressant Response: Association of TREKI and Treatment Resistance in the STAR*D Study
}

\author{
Roy H Perlis*,1,2,3, Priya Moorjani' ${ }^{2}$, Jesen Fagerness ${ }^{2}$, Shaun Purcell ${ }^{2}$, Madhukar H Trivedi ${ }^{4}$, Maurizio Fava', \\ A John Rush ${ }^{4,5}$ and Jordan W Smoller ${ }^{2,3}$ \\ 'Depression Clinical and Research Program, Massachusetts General Hospital and Harvard Medical School, Boston, MA, USA; ${ }^{2}$ Psychiatric \\ and Neurodevelopmental Genetics Unit, Center for Human Genetic Research, Massachusetts General Hospital, Boston, MA, USA; ${ }^{3}$ Department \\ of Psychiatry, Psychiatric Genetics Program in Mood and Anxiety Disorders, Massachusetts General Hospital, Boston, MA, USA; ${ }^{4}$ Department of \\ Psychiatry, University of Texas Southwestern Medical Center at Dallas, Dallas, TX, USA; ${ }^{5}$ Department of Clinical Sciences, University of Texas \\ Southwestern Medical Center at Dallas, Dallas, TX, USA
}

Recent rodent models of antidepressant response implicate a novel set of genes in mechanisms of antidepressant action. The authors examined variants in four such genes (KCNK2 (TREKI), SLCI8A2 (VMAT2), S100A 10, and HDAC5) for association with remission in a large effectiveness trial of antidepressant treatments. Subjects were drawn from the Sequenced Treatment Alternatives to Relieve Depression (STAR*D) study, a multicenter, prospective, effectiveness trial in major depressive disorder (MDD). Outpatients with nonpsychotic MDD were initially treated with citalopram for up to 14 weeks; those who did not remit with citalopram were sequentially randomized to a series of next-step treatments, each for up to 12 weeks. Single-nucleotide polymorphisms in four genes were examined for association with remission, defined as a clinician-rated Quick Inventory of Depressive Symptomatology (QIDS- $\left.C_{16}\right)$ score $\leqslant 5$. Of I 554 participants for whom DNA was available, 565 (36\%) reached remission with citalopram treatment. No association with any of the four genes was identified. However, among the 751 who entered next-step treatment, variants in KCNK2 were associated with treatment response (Bonferroni-corrected, gene-based empirical $p<0.001$ ). In follow-up analyses, KCNK2 was also associated with effects of similar magnitude for third-step treatment among those with unsatisfactory benefit to both citalopram and one next-step pharmacotherapy $(n=225)$. These findings indicate that genetic variation in KCNK2 may identify individuals at risk for treatment resistance. More broadly, they indicate the utility of animal models in identifying genes for pharmacogenetic studies of antidepressant response.

Neuropsychopharmacology (2008) 33, 2810-2819; doi: 10.1038/npp.2008.6; published online 20 February 2008

Keywords: depression; genetic; treatment-resistant; SSRI

\section{INTRODUCTION}

Individual response to antidepressant treatment is highly variable, and is influenced by such factors as adequacy of dose, adherence, and sociodemographic features (Trivedi et al, 2006b). Genetic variation has also been suggested to influence antidepressant response, in terms of both symptomatic improvement and tolerability (Malhotra et al, 2004; McMahon et al, 2006; Murphy et al, 2003; Perlis, 2007). However, the ability to identify suitable candidate genes for study has been hindered by the relatively limited understanding of antidepressant mechanism of action, as well as a

*Correspondence: Dr RH Perlis, Massachusetts General Hospital, 15 Parkman Street, WACC 812, Boston, MA 021 I4, USA,

Tel: + 6177267426 , Fax: + I 6177243028 ,

E-mail: rperlis@partners.org

Received 17 October 2007; revised 30 November 2007; accepted 8 December 2007 lack of large prospective cohorts of patients receiving homogeneous antidepressant treatment.

Most antidepressant pharmacogenetic studies have therefore focused on monoaminergic genes, particularly those related to the proximal action of selective serotonin reuptake inhibitors (SSRIs) (Schafer, 1999). While some such studies have yielded evidence of association, the implicated genes account for only a small proportion of the observed variation in response (McMahon et al, 2006; Serretti et al, 2006).

Recently, mouse models of depression and antidepressant response have provided compelling evidence implicating four genes in the biology of antidepressant response (Crowley et al, 2006; Heurteaux et al, 2006; Svenningsson et al, 2006; Tsankova et al, 2006). KCNK2 (also referred to as TREK1) is a neuronal background potassium channel that is widely expressed in the brain (Honore, 2007). TREK1 is inhibited by therapeutic doses of SSRIs, and mice lacking 
the TREK1 gene exhibit a depression-resistant phenotype that mimics treatment with antidepressants (Heurteaux et al, 2006). These mice are insensitive to treatment with SSRI antidepressants, suggesting that the therapeutic effects of SSRIs are mediated through TREK1. The monoamine transporter VMAT2 (encoded by SLC18A2) also plays a key role in pathways relevant to antidepressant action by loading monoaminergic neurotransmitters into presynaptic vesicles. A quantitative trait locus underlying citalopram response in mice has been mapped to a region containing VMAT2, and two missense polymorphisms in mouse VMAT2 were identified (Crowley et al, 2006). Similarly, p11 (encoded by S100A10) was strongly implicated in the biology of depression and antidepressant effects through its dynamic modulation of $5 \mathrm{HT} 1 \mathrm{~B}$ receptors. The $\mathrm{p} 11$ protein, which enhances the signaling efficacy of 5HT1B receptors and increases the number of $5 \mathrm{HT} 1 \mathrm{~B}$ receptors on neuronal cell surfaces, is downregulated in rodent models of depression and in brain tissue from depressed patients, but upregulated in response to antidepressants and electroconvulsive therapy. Mice lacking p11 exhibit a depression-like phenotype and are resistant to antidepressant treatment (Svenningsson et al, 2006). Finally, a histone deacetylase, $H D A C 5$, has been implicated in the antidepressant-like effects of imipramine mediated via brainderived neurotrophic factor in a mouse depression model (Tsankova et al, 2006). Despite this compelling evidence of involvement in antidepressant mechanisms from mouse models, none of these four loci have been examined as genetic predictors of human antidepressant response.

Most antidepressant pharmacogenetic studies to date have focused on response to a single trial of a single agent, typically an SSRI. However, in clinical practice, most patients will not achieve remission after an initial antidepressant trial (Fava and Davidson, 1996; Trivedi et al, 2006b). As a result, there has been increasing emphasis on clinical implications and management of treatment resistance, that is, failure to remit despite two adequate antidepressant trials. Treatment-resistant depression has been associated with poor prognosis and substantial economic costs (Souery et al, 2006).

The Sequenced Treatment Alternatives to Relieve Depression $\left(\mathrm{STAR}^{\star} \mathrm{D}\right)$ study, a large multicenter, multistep series of randomized, controlled treatments given to outpatients with nonpsychotic major depressive disorder (MDD), has demonstrated that a substantial proportion of depressed patients do not achieve remission of MDD even after sequential treatment trials (Fava et al, 2003; Rush et al, 2004; Trivedi et al, 2006b). As the largest study of its kind, $\mathrm{STAR}^{\star} \mathrm{D}$ provides a unique opportunity to study treatment resistance. Here, we report that a genetic analysis of candidate loci derived from mouse models of antidepressant treatment demonstrates association between KCNK2 and treatment resistance in the $\operatorname{STAR}^{\star} \mathrm{D}$ cohort.

\section{PATIENTS AND METHODS}

\section{Clinical Methods}

In the $\mathrm{STAR}^{\star} \mathrm{D}$ multicenter trial, patients were initially treated with the SSRI citalopram. Those who were intolerant of citalopram, or who did not achieve remission, were then randomized to a next-step treatment option. The methods of the STAR ${ }^{\star} \mathrm{D}$ study are described in detail elsewhere (Fava et al, 2003; Rush et al, 2004; Trivedi et al, 2006b) and are summarized below.

\section{Study Organization}

The STAR ${ }^{\star} \mathrm{D}$ study, overseen by 14 regional centers (RCs), provided treatment at 41 clinical sites (18 primary care and 23 psychiatric care settings) across the United States.

Research outcomes were collected by telephone interviews conducted by a small team of trained research outcome assessors (ROAs) masked to treatment, and by telephone-based interactive voice response. ROAs received extensive training in the administration of efficacy measures, with inter-rater reliability assessed periodically.

\section{Study Population}

This report primarily presents data from the 1554 citalopram-treated participants for whom DNA was available to us and who met $\mathrm{STAR}^{\star} \mathrm{D}$ entry criteria requiring HAM-D-17 $\geqslant 14$, as well as a subset of 751 participants who entered the second-step (level 2) treatment. Exploratory analysis also considered the 225 participants who entered level 3 treatment. As the study was designed to represent real-world clinical practice, only individuals who sought treatment at the clinical sites were recruited and advertising was not permitted. Participants were informed of all risks, benefits, and adverse events associated with each study treatment, and they provided written informed consent prior to study entry at each level, as well as for the genetic study. Participants could decline participation in the genetic protocol, which was initiated about 12 months after the clinical study initiation. The study protocol was approved by institutional review boards at all participating RCs, the National Coordinating Center, and the Data Coordinating Center. The study was overseen by an NIMH DSMB.

Participants met broadly inclusive and minimally exclusive criteria to enroll a representative sample. Men and women outpatients, age 18-75 years, with a DSM-IV diagnosis of nonpsychotic MDD, a baseline score $\geqslant 14$ on the 17-item Hamilton Rating Scale for Depression (HRSD) (Hamilton, 1960) by the Clinical Research Coordinator (CRC), and for whom the treating clinician had determined that outpatient antidepressant treatment was safe and appropriate were enrolled. Exclusion criteria included a well-documented history of nonresponse or intolerability in the current major depressive episode to adequate doses (Fava, 2003) of one or more medications utilized in the first two treatment steps; lifetime diagnosis of MDD with psychotic features, schizophrenia, schizoaffective disorder, or bipolar disorder; a current primary diagnosis of eating disorder or obsessive-compulsive disorder; presence of severe, unstable concurrent psychiatric conditions likely to require hospitalization within 6 months (eg, severe alcohol dependence with recent detoxification admissions); presence of concurrent medical or psychiatric conditions or concomitant medications that contraindicate a protocol treatment; and pregnancy or intent to conceive within the 9 months subsequent to study entry. 


\section{Research Outcome Assessments}

The CRC at each study site completed the $\mathrm{HRSD}_{17}$ at baseline, reviewed inclusion/exclusion criteria, and completed the 16-item Quick Inventory of Depressive Symptomatology (QIDS-C 16 ) (Rush et al, 2000, 2003, 2006a; Trivedi et al, 2004) - a clinician-rated scale that assesses nine diagnostic symptoms/domains of MDD - at each treatment visit. The QIDS- $\mathrm{C}_{16}$ was used to guide treatment implementation and dose adjustment (Rush et al, 2006c; Trivedi et al, 2006a).

The ROA conducted a telephone interview with study participants within $72 \mathrm{~h}$ of the baseline and subsequent visits to complete the baseline $\mathrm{HRSD}_{17}$ and the 30 -item Inventory of Depressive Symptomatology - Clinician-Rated (IDS-C ${ }_{30}$ ) (Rush et al, 1996).

\section{Intervention}

Details of the $\mathrm{STAR}^{\star} \mathrm{D}$ measurement-based care approach have been described elsewhere (Trivedi et al, 2006b). Following citalopram treatment at doses up to $60 \mathrm{mg}$ for up to 14 weeks, participants who did not achieve remission (QIDS-C $\leqslant 5$ ) and/or who could not tolerate citalopram were encouraged to proceed to next-step treatments. Participants could discontinue citalopram before 12 weeks in the event of intolerable side effects requiring change in medication, inability to increase to an optimal dose because of side effects or patient preference, or presence of significant depressive symptoms (defined as QIDS- $\mathrm{C}_{16} \geqslant 9$ ) after 9 weeks at maximum tolerated dose. Available options at level 2 included four treatment switches (discontinuation of citalopram with initiation of bupropion-sustained release, sertraline, venlafaxine-extended release, or cognitive therapy) and three augmentation strategies (continuation of citalopram with addition of bupropion-sustained release, buspirone, or cognitive therapy). To better mimic clinical practice, on entry into the second-step (level 2) treatment, participants could indicate which strategies were acceptable to them, and were randomized among these options (Lavori et al, 2001). Similarly, those who did not remit, or could not tolerate, the second-step treatment were encouraged to enter the third medication step (level 3) treatment. Available options included augmentation with lithium or thyroxine and switch to mirtazapine or nortriptyline.

Concomitant treatments for current general medical conditions, for associated symptoms of depression, including insomnia, anxiety, and agitation, and for antidepressant-associated side effects were permitted based on clinical judgment. However, stimulants, anticonvulsants, antipsychotics, alprazolam, nonprotocol antidepressants other than $\leqslant 200 \mathrm{mg}$ trazodone at bedtime for insomnia, and psychotherapies targeted at depressive symptoms were not permitted (Trivedi et al, 2006b).

\section{Genotyping Methods}

We initially identified single-nucleotide polymorphisms (SNPs) in these four genes and $10 \mathrm{~kb}$ flanking regions $(395.9 \mathrm{~kb}$ in all) using the International HapMap Project Phase II database (http://www.hapmap.org), which yielded a total of 374 SNPs. The Tagger program (http://www.broad. mit.edu/mpg/tagger/) (de Bakker et al, 2005), which examines pairwise and multiallelic linkage disequilibrium to determine the minimum set of SNPs necessary to capture all common genetic variation in a region, identified 50 tagging SNPs sufficient to capture all HapMap SNPs with minor allele frequency greater than $5 \%$ among Caucasian Europeans in these genes with a minimum $r^{2}$ of 0.8 (or 0.5 in $K C N K 2$, where the number of HapMap SNPs was substantially greater and resource limitations precluded more complete coverage) (Supplementary Table 1). Any putative functional SNPs, that is, those in the promoter or exons, according to dbSNP, were 'forced' to be selected as tags. The tagging approach has been shown to be efficient and powerful for association studies (de Bakker et al, 2005).

Genotyping was performed using the methods described previously (Sklar et al, 2002). Primers were designed using SpectroDESIGNER software (Sequenom, San Diego, CA, USA). Polymerase chain reaction was performed followed by homogeneous MassEXTEND reaction. Samples were analyzed in automated mode by a MassARRAY RT mass spectrometer (Sequenom) (Buetow et al, 2001). The resulting spectra were analyzed by SPECTROTYPER software (Sequenom) after baseline correction and peak identification. SNPs successfully genotyped in fewer than $85 \%$ of subjects, with minor allele frequency less than $5 \%$ or deviating significantly from the Hardy-Weinberg equilibrium (HWE) $(p<0.0001)$, were excluded (the latter threshold was selected because of the possibility that these genes could represent liability genes for MDD itself and diverge from HWE). Likewise, participants with less than $80 \%$ successful genotypes $(n=28)$ were excluded from further analysis. For the remaining 41 SNPs, successful genotyping rates were $>95 \%$, and rates of missingness were not significantly different $(p<0.05)$ between remitters and nonremitters. Concordance for duplicate DNAs $(n=4)$ was $100 \%$. Tagging performance for these SNPs in CaucasianEuropean and Yoruban cohorts in HapMap is presented in Supplementary Table 1.

\section{Analytic Methods}

For clinical predictors of treatment response, even subtle differences in response definitions have been shown to markedly influence results (Tedlow et al, 1998). For primary analyses, we utilized protocol-specified definitions of treatment remission. Tolerability was determined according to an algorithm developed by the principal investigator and statistician of the $S_{T A R}{ }^{*} \mathrm{D}$ study as well as the principal investigators of the ancillary genetic studies prior to analysis (McMahon et al, 2006). This algorithm assigns tolerability status based upon willingness to continue current treatment at level completion (ie, to pursue augmentation), reported reasons for exiting study level, duration of treatment prior to discontinuation, and patientreported global rating of side effect burden. Remission was defined as QIDS- $\mathrm{C}_{16} \leqslant 5$ at final visit for a given level, and contrasted with nonremission (QIDS- $\mathrm{C}_{16}>5$ ). As an effectiveness study, $\mathrm{STAR}^{\star} \mathrm{D}$ did not include detailed measures of adherence, although significant nonadherence could be recorded as a reason for exiting treatment.

Two sets of primary analysis were performed, examining two related but distinct phenotypes. First, we examined 
remission with citalopram treatment. However, we also focused on level 2 treatment outcomes because a substantial proportion of response to an initial antidepressant trial may be placebo-like or nonspecific (Walsh et al, 2002). Therefore, while this cohort is smaller than that available in level 1 , we hypothesized that elimination of placebo responders would improve power to detect true associations. To further maximize power, we pooled the level 2 treatment arms. For loci that showed evidence of association, follow-up comparisons between specific treatments were conducted as described below. Finally, as the primary motivation for these analyses was to evaluate pharmacotherapy, individuals who received cognitive therapy (either alone or in combination with citalopram) at level 2 were excluded from analysis.

\section{Gene-Based Analyses}

As suggested by Neale and Sham (2004) for analysis of association studies, we considered the unit of analysis in this study to be the single gene, rather than single SNP. Therefore, primary analysis screened for association using the set-based test, implemented in PLINK (Purcell et al, 2007) (http://pngu.mgh.harvard.edu/ purcell/plink/) for each gene. Where multiple SNPs within a gene influence a given phenotype, this test may offer better power to screen for associations than single-SNP tests. In brief, this test, analogous to that proposed by Ott and Hoh (2003), computes the test statistics ( $\chi^{2}$ for dichotomous outcomes) for each individual SNP within a gene, then calculates the average test statistic for the best single SNP per region, for the best two SNPs per region, and for the best three SNPs per region. The significance of these set statistics is then estimated by permutation, which allows a determination of gene-wise significance, allowing for correlation between SNPs and tests, while controlling type 1 error at the singlegene level. For these analyses, significance of SNP combinations, including between 1 and 3 SNPs, was estimated, using 10000 permutations. To further control type 1 error, permutation was used to account for all tests in all genes (yielding experiment-wide $p$-values), and then further Bonferroni correction was applied for the number of primary phenotypes (2, corresponding to level 1 and level 2 outcomes). Where a gene met this threshold (ie, experiment-wide permuted $p<0.025$ ), all single-SNP associations in that gene were then examined. For illustrative purposes, a Kaplan-Meier survival curve was generated for one of these significant SNPs.

To examine possible confounders or modifiers of effect, we performed a series of planned follow-up analyses for any SNPs in genes with nominal evidence of association. First, to address the possible confounding effects of intolerance, in which individuals appear to be nonresponders because they drop out early in treatment or are bothered by significant adverse effects, we examined associations with the intolerance phenotype described above, and with time in level 2 treatment. Second, we repeated analyses omitting the 44 subjects who were discontinued from level 2 treatment because of nonadherence. Third, we adjusted for adjunctive benzodiazepine use among 175 patients $(23 \%)$.
We also examined possible sources of heterogeneity of effect. As individuals opting for switch $v s$ augmentation differed in clinical characteristics (Trivedi et al, 2006a; Wisniewski et al, in press), we tested for heterogeneity in the odds ratio of association between the subset of individuals who received a 'switch' and those who received 'augmentation.' Likewise, we tested for heterogeneity in the odds ratio of association between those who received serotonergic interventions and those who received (in addition) dopaminergic or noradrenergic interventions. The latter analysis considered switch to sertraline and buspirone augmentation as one stratum, and switch to venlafaxine-XR or bupropion-SR or bupropion-SR augmentation as another stratum. Examination of geneby-treatment interactions utilized the Breslow-Day test for heterogeneity of odds ratios, also conducted using PLINK. Where this test was significant at $p<0.1$, rejecting homogeneity of odds ratios, we planned analyses of association within each stratum. For any gene associated with level 2 outcome, we also examined its impact in level 3, hypothesizing that we should see similar effects.

For consistency with previous $\mathrm{STAR}^{\star} \mathrm{D}$ pharmacogenetic reports (McMahon et al, 2006), primary analyses pooled subjects from all ethnicities to maximize power to detect associations. To address the possibility that racial admixture could lead to spurious association, we repeated the primary analyses using the Caucasian-only cohort and examined heterogeneity of effect between Caucasian and non-Caucasian cohorts. For descriptive purposes, we also include analyses of the second-largest ethnic group, those individuals of African-American origin. We also examined single-SNP associations after adjusting for ethnic origin using a panel of ancestry-informative markers, as described in a previous report (McMahon et al, 2006).

\section{RESULTS}

The STAR ${ }^{\star} \mathrm{D}$ genetic sample was broadly similar to the total $\mathrm{STAR}^{\star} \mathrm{D}$ population in sociodemographic and clinical features, as described elsewhere (McMahon et al, 2006). For the treatment outcome cohort, DNA was available for 1554 citalopram-treated subjects who met protocol-specified entry criteria. Of these individuals, 565 (36\%) reached remission with citalopram treatment. Among nonremitters, 751 received a pharmacotherapeutic intervention at level 2, of whom $264(35 \%)$ reached remission. Sociodemographic and clinical features of these individuals are summarized in Table 1 (additional details of the genetics cohort are presented by McMahon et al (2006) and Perlis (2007)).

Table 2 shows results from the set-based test for the level 1 outcomes, indicating that we did not observe evidence of association with any of the four loci. Table 3 likewise shows results from the set-based test for association with protocol-defined remission at level 2. One gene, $K C N K 2$, met the threshold for further examination. Four SNPs in KCNK2 showed nominal $p \leqslant 0.01$ for association with remission; none of these diverged significantly from HWE $(p>0.05)$ (see Figure 1). Covarying by sex, age, or presence or absence of comorbid anxiety disorder yielded similar results (data not shown). Confining the analyses only to Caucasian subjects yielded similar effect sizes, as did 
Table I Clinical and Sociodemographic Features of Cohorts Used for Analyses of Level I, 2, and 3 Outcomes

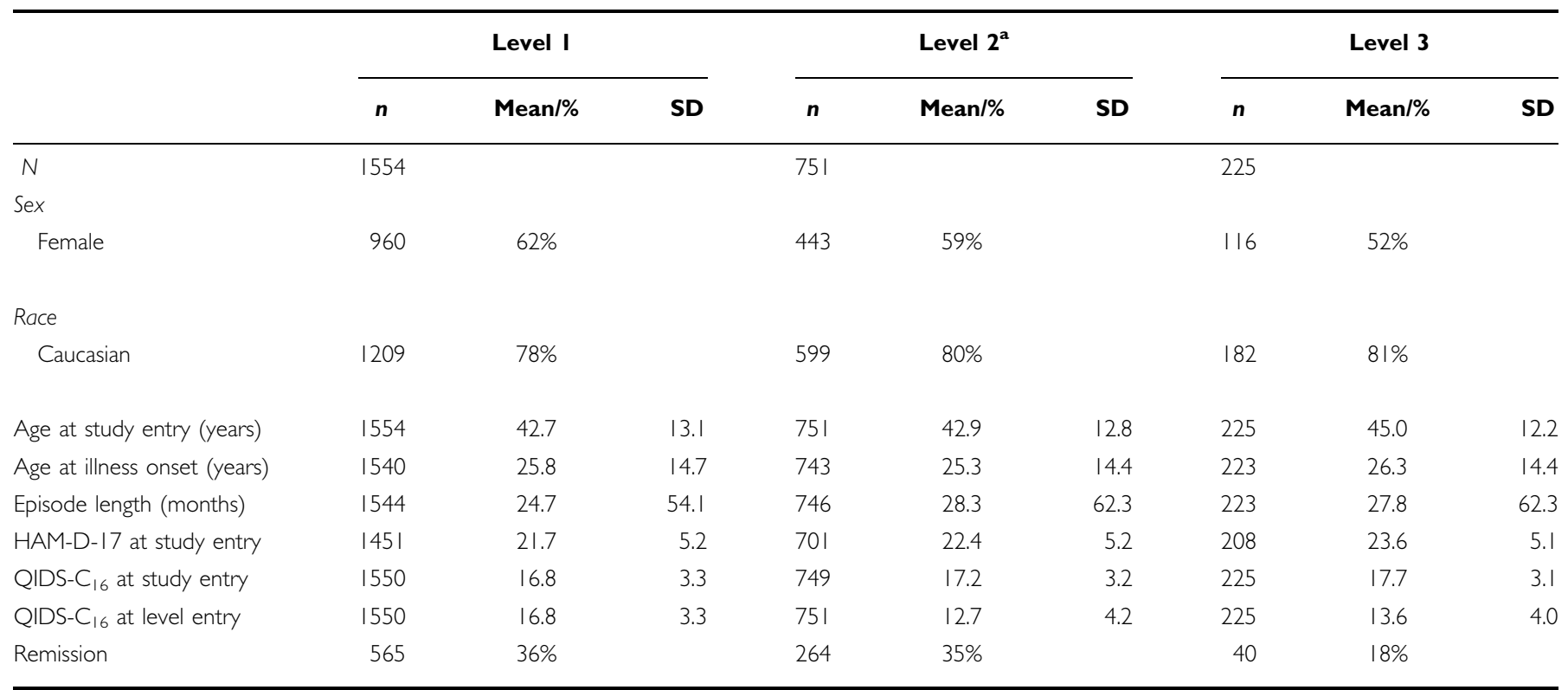

Summary of clinical and sociodemographic features for the genetics cohort as a whole (level I), and the subsets used for the level 2 and 3 analyses.

a'Excluding individuals randomized to cognitive therapy.

Table 2 Set-Based Test of Association with Remission in Level I

\begin{tabular}{|c|c|c|c|c|}
\hline Gene & SNP & $\chi^{2}$ & P_gene & P_experiment \\
\hline \multirow[t]{3}{*}{ SIOOAIO } & rs I I 204922 & 0.93 & 0.74 & 1.00 \\
\hline & rs|552607 & 0.71 & 0.71 & 0.99 \\
\hline & rs 12083193 & 0.62 & 0.65 & 0.98 \\
\hline \multirow[t]{3}{*}{ KCNK2 (TREKI) } & rs 10779646 & 3.92 & 0.17 & 0.53 \\
\hline & rs 17546779 & 3.05 & 0.14 & 0.47 \\
\hline & rs $284 \mid 608$ & 2.65 & 0.09 & 0.33 \\
\hline \multirow[t]{3}{*}{ SLCI 8A2 (VMAT2) } & rs|4240 & 2.96 & 0.28 & 0.73 \\
\hline & rs|860404 & 2.83 & 0.16 & 0.50 \\
\hline & rs363226 & 2.78 & 0.07 & 0.26 \\
\hline \multirow[t]{3}{*}{ HDAC5 } & rs8065686 & 1.42 & 0.59 & 0.97 \\
\hline & rs228769 & 0.99 & 0.58 & 0.97 \\
\hline & rs38I5076 & 0.74 & 0.57 & 0.96 \\
\hline
\end{tabular}

P_gene refers to empirical $p$-value for that SNP or set of SNPs, adjusted for all other I-, 2-, or 3-SNP sets in that gene.

P_experiment refers to empirical $p$-value for that SNP or set of SNPs, adjusted for all tests in all genes.

Results of applying a set-based test, which examines $\chi^{2}$ for association between each individual SNP and the phenotype of interest (here remission in level I of STAR*D). $P$-values are then calculated by permutation examining the mean $\chi^{2}$ of each I-, 2-, and 3-SNP combination. In the table, P (gene) refers to empirical $p$-value adjusted for all other SNPs or sets of SNPs in the gene. $\mathrm{P}$ (experiment) refers to empirical $p$-value adjusted for all SNPs or sets of SNPs in the four genes in this experiment. See text for details.

adjusting for ancestry-informative markers in a regression analysis (Table 4). Overall, odds of remission were $60-90 \%$ greater among individuals carrying risk alleles at any of the four SNPs.
Table 3 Set-Based Test of Association with Remission in Level 2

\begin{tabular}{|c|c|c|c|c|}
\hline Gene & SNP & $\chi^{2}$ & $P_{-}$gene & P_experiment \\
\hline \multirow[t]{3}{*}{ SIOOAIO } & rs I212837| & 0.28 & 0.9419 & 1.0000 \\
\hline & rs2999528 & 0.18 & 0.9475 & 1.0000 \\
\hline & rs6587640 & 0.15 & 0.9380 & 1.0000 \\
\hline \multirow[t]{3}{*}{ KCNK2 (TREKI) } & rs 12136349 & 9.02 & 0.0115 & 0.0480 \\
\hline & rs2841616 & 9.01 & 0.0024 & 0.0096 \\
\hline & rs284I608 & 8.98 & 0.0002 & 0.0009 \\
\hline \multirow[t]{3}{*}{ SLCI BA2 (VMAT2) } & rs4752045 & 4.65 & 0.1091 & 0.3698 \\
\hline & rs|860404 & 3.23 & 0.1003 & 0.3454 \\
\hline & rs225532I & 2.71 & 0.0664 & 0.2376 \\
\hline \multirow[t]{3}{*}{ HDAC5 } & rs228769 & 1.20 & 0.6501 & 0.9848 \\
\hline & rs8065686 & 1.15 & 0.5248 & $0.949 \mid$ \\
\hline & rs38I5076 & 0.88 & 0.4973 & 0.9369 \\
\hline
\end{tabular}

P_gene refers to empirical $p$-value for that SNP or set of SNPs, adjusted for all other 1-, 2-, or 3-SNP sets in that gene.

P_experiment refers to empirical $p$-value for that SNP or set of SNPs, adjusted for all tests in all genes.

Results of applying a set-based test for association with remission in level 2 of STAR*D.

To address the possibility that remission was confounded by medication intolerance, we further examined these individual SNPs for evidence of association with medication tolerability. No significant associations were found with tolerability or total time-in-treatment, suggesting that the observed association with efficacy is not mediated by differences in time on protocol (Supplementary Table 2). Including presence or absence of sedative/hypnotic (benzodiazepine or trazodone) cotreatment as a covariate likewise 
Table 4 Single-SNP Associations with Level 2 and Level 3 Remission

\begin{tabular}{|c|c|c|c|c|c|c|c|c|c|c|c|c|c|c|c|}
\hline \multirow{2}{*}{ SNP details } & \multirow[b]{2}{*}{$\begin{array}{l}\text { Location } \\
\text { (hg|6) }\end{array}$} & \multirow[b]{2}{*}{$\begin{array}{l}\text { Putative function } \\
\text { (dbSNP) }\end{array}$} & \multirow[b]{2}{*}{ Minor allele } & \multirow[b]{2}{*}{$\begin{array}{l}\text { Frequency } \\
\text { (case) }\end{array}$} & \multirow[b]{2}{*}{$\begin{array}{l}\text { Frequency } \\
\text { (control) }\end{array}$} & \multirow[b]{2}{*}{$\begin{array}{l}\text { Major } \\
\text { allele }\end{array}$} & \multicolumn{3}{|c|}{$\begin{array}{c}\text { Remission (level 2) } \\
\text { Entire cohort }\end{array}$} & \multicolumn{2}{|c|}{$\begin{array}{c}\text { Remission (level 2) } \\
\text { Adjusted (ancestry panel) }\end{array}$} & \multicolumn{2}{|c|}{$\begin{array}{c}\text { Remission (level 2) } \\
\text { Caucasian cohort }\end{array}$} & \multicolumn{2}{|c|}{ Remission (level 3) } \\
\hline & & & & & & & $\chi^{2}$ & $p$-value & OR & $p$-value & OR & $p$-value & OR & $p$-value & OR \\
\hline rs/203/300 & chrl:21 I 559940 & & $A$ & 0.22 & 0.25 & G & 1.26 & 0.2611 & 0.86 & 0.099 & 0.79 & 0.1760 & 0.82 & 0.24 & 0.69 \\
\hline rs 2841616 & chrl:21 I562233 & & G & 0.51 & 0.42 & $A$ & 9.01 & 0.0027 & 1.41 & 0.012 & 1.37 & 0.0075 & 1.41 & 0.04 & 1.68 \\
\hline rs7538655 & chrl:211567219 & & $A$ & 0.23 & 0.26 & G & 1.39 & 0.2380 & 0.85 & 0.372 & 0.89 & 0.0343 & 0.73 & 0.77 & 1.09 \\
\hline rs $284 \mid 608$ & chrl:21 I579642 & & C & 0.52 & 0.44 & $A$ & 8.92 & 0.0028 & 1.40 & 0.008 & 1.39 & 0.0062 & 1.41 & 0.14 & 1.45 \\
\hline rs I 7546779 & chrl:211619803 & & C & 0.06 & 0.05 & $\mathrm{~T}$ & 0.96 & 0.3262 & 1.27 & 0.399 & 1.24 & 0.2909 & 1.31 & 0.69 & 0.77 \\
\hline rs 12136349 & chrl:21 I 639622 & Promoter & $A$ & 0.25 & 0.32 & G & 9.02 & 0.0027 & 0.68 & 0.008 & 0.70 & 0.0158 & 0.70 & 0.09 & 0.62 \\
\hline rs 10779646 & $\operatorname{chrl}: 211714630$ & coding exon & G & 0.37 & 0.43 & $A$ & 4.48 & 0.0342 & 0.78 & 0.257 & 0.87 & 0.1228 & 0.81 & 0.67 & 0.89 \\
\hline rs7549|84 & chrl:21 I80130| & $3^{\prime}$ UTR & G & 0.22 & 0.27 & A & 4.80 & 0.0284 & 0.74 & 0.174 & 0.82 & 0.2355 & 0.83 & 0.01 & 0.40 \\
\hline rs 10494996 & chrl:21 I 808066 & & A & 0.16 & 0.11 & G & 6.48 & 0.0109 & 1.53 & 0.025 & 1.47 & 0.0614 & 1.39 & 0.02 & 2.13 \\
\hline
\end{tabular}

Abbreviation: OR, odds ratio.

5HT vs NE/DA: primarily serotonergic vs noradrenergic/dopaminergic antidepressant treatment.

Results of examining association between single SNPs in KCNK2/TREKI and the primary outcome (level 2 remission) and secondary measures of interest. P-values are presented without correction, as these tests were only performed because the gene itself showed evidence of association in primary analysis.

Bold value signifies $P<0.05$
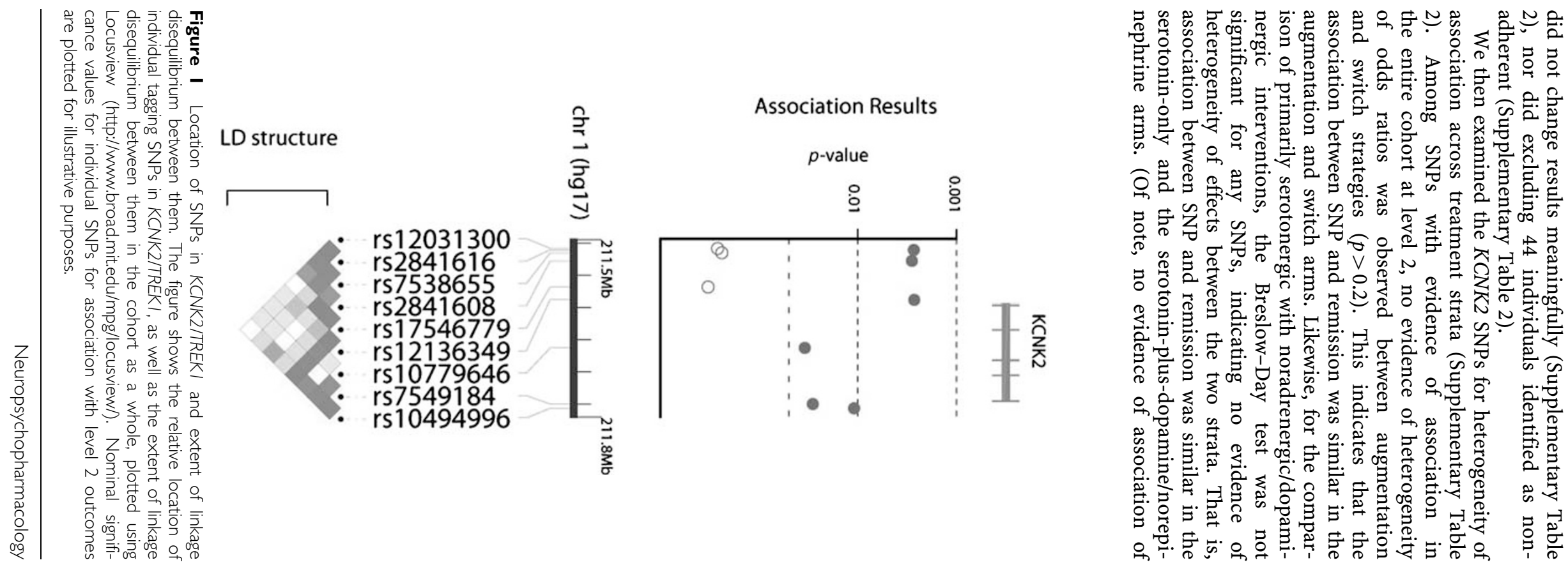
KCNK2 with treatment response was observed among the 71 successfully genotyped patients who received cognitive therapy with or without citalopram at level 2 and who were omitted from primary analyses (Supplementary Table 2).)

As an exploratory analysis, we examined the SNPs in KCNK2 for association with remission among the 225 participants who entered a level 3 treatment and who met entry and genotyping quality criteria. Odds ratios for remission at level 3 were consistent with those observed at level 2 for the KCNK2 SNPs; that is, the direction and magnitude of effect for all of these SNPs was generally similar (Table 4).

\section{DISCUSSION}

We observed association between genetic variants in the KCNK2 (TREK1) locus and resistance to multiple antidepressant classes. To our knowledge, this study is one of the first to examine candidate genes derived from mouse models of antidepressant response, validating the utility of such models for understanding the genetic basis of human antidepressant response. In addition, this study is one of the first to examine the pharmacogenetics of treatment resistance in MDD, an area of significant clinical importance (Fava, 2003).

Specifically, we identified association between four SNPs in KCNK2 and differential response to next-step treatment among individuals who did not remit with citalopram treatment. Associations of similar magnitude were also observed with nonremission after a third treatment trial. These effects appeared to be independent of treatment arm (augmentation $v s$ switch) or primary treatment target (serotonin alone or with norepinephrine/dopamine) in level 2. These associations also did not appear to arise as a result of differences in depression severity, overall treatment tolerability, or benzodiazepine use.

The KCNK2 gene represents a compelling candidate for influencing antidepressant treatment response based on data from animal models. KCNK2 codes for a potassium background channel whose activity is regulated by a diverse array of cellular signals, notably including receptors of the serotonergic (5HT4) and glutamatergic (mGluR1 and mGluR5) systems (Fink et al, 1996; Honore, 2007; Lopes et al, 2005; Murbartian et al, 2005). It is expressed in brain areas implicated in MDD, including prefrontal cortex, hippocampus, and other limbic system structures (Fink et al, 1996; Honore, 2007; Talley et al, 2001). It was recently demonstrated that mice lacking the KCNK2 gene are resistant to developing a depressive phenotype in five different stressor models, and display a blunted cortisol response to stress (Heurteaux et al, 2006). Moreover, they exhibit behaviors similar to those seen in wild-type mice treated with standard antidepressants on tasks such as the forced swim test and novelty-suppressed feeding (Porsolt et al, 1977; Santarelli et al, 2003).

The bulk of evidence to date implicates KCNK2 in serotonergic antidepressant effect (Gordon and Hen, 2006). In the TREK 1 -knockout mouse, firing rates of serotonergic neurons in the dorsal raphe nucleus are increased compared to wild-type mice; depletion of serotonin in these mice eliminates the antidepressant-like phenotype (Heurteaux et al, 2006). Most directly, KCNK2 is known to be directly inhibited by fluoxetine and other SSRIs (Kennard et al, 2005). However, the impact of other antidepressant classes is less well-studied. Our results suggest that KCNK2 may be involved in a final common pathway of antidepressant response, at least among those with monoaminergic effects.

We did not identify an association between $K C N K 2$ and outcome of citalopram treatment at level 1 of STAR ${ }^{\star} D$ after correction for multiple comparisons. This may be a consequence of the prevalence of drug-nonspecific response during initial treatment; that is, many patients considered remitters at level 1 actually would have remitted with a placebo, or perhaps with no treatment (Walsh et al, 2002). Such misclassification would substantially diminish power to detect associations. Eliminating placebo responders should yield a more homogeneous subgroup for analysis in level 2 treatment, and consequently improve power to detect true associations.

As well, we detected no association either with citalopram response or with treatment resistance for other genes implicated in mouse models of antidepressant response, including SLC18A2 (VMAT2), S100A10, and HDAC5. Tagging efficiency for these genes was quite good (Supplementary Table 1), suggesting that we were able to capture the majority of common variation in these genes, but we cannot exclude the possibility that less common variations in these genes would contribute to differential treatment outcome.

The central caveat in considering our findings, as with most previous reports, is the substantial risk of spurious association (Sullivan, 2007). The STAR ${ }^{\star} \mathrm{D}$ genetics cohort is being studied independently by multiple groups, using both candidate-based and genome-wide approaches. While we focused on a limited number of hypotheses and used permutation to control error at the experiment-wise level, which accounts for examining multiple SNPs in multiple genes, replication is essential before clinical application could be contemplated. We also cannot fully account for effects of population stratification, although we found no evidence of confounding using subgroup analyses or ancestry-informative markers. Our analyses were restricted to a single cohort because we could identify no adequately powered cohort of SSRI nonresponders available for comparable study. Given the high clinical significance of treatment resistance, collection of such cohorts for pharmacogenetic studies is sorely needed. In addition, as the SNPs in KCNK2 were selected to capture common variation rather than because any have an obvious function, further study will be required to identify 'causal' SNPs. We note that significant evidence of association was detected for one promoter SNP, with more modest evidence for a synonymous coding SNP.

In the absence of a placebo arm, we also cannot determine whether the observed associations are truly treatmentspecific. Indeed, the tests for heterogeneity of odds ratios across strata indicate that the associations are not limited to individual treatment strategies. However, the absence of association in level 1 does suggest some degree of specificity; if KCNK2 SNPs were associated with shorter episode duration, for example, we would have expected to see effects at level 1 as well. 
Clinically, treatment-resistant depression, typically defined as the failure to respond to at least two antidepressant trials of adequate dose and duration (Souery et al, 2006), is prevalent (Fava and Davidson, 1996) and has important and worrisome implications (Fava, 2003). Treatment-resistant MDD contributes substantially to the costs and disability associated with MDD (Crown et al, 2002). In the $\mathrm{STAR}^{\star} \mathrm{D}$ clinical cohort as a whole, individuals who did not adequately benefit from the first two treatments had less than a $15 \%$ likelihood of responding to subsequent interventions (Rush et al, 2006b). If these high-risk individuals could be identified by combining previously reported tests associated with poorer SSRI response (McMahon et al, 2006; Serretti et al, 2006), with one based on the present findings, they might be stratified to more aggressive or intensive early treatment.

More broadly, these results suggest the utility of animal models of antidepressant treatment in identifying candidate genes for study in humans. Particularly, in the context of previous animal studies implicating KCNK2 in antidepressant response, our results further highlight the potential importance of this gene in understanding antidepressant response in humans.

\section{ACKNOWLEDGEMENTS}

The Sequenced Treatment Alternatives to Relieve Depression $\left(\mathrm{STAR}^{\star} \mathrm{D}\right)$ study is supported by federal funds from NIMH under contract N01 MH-90003 to the University of TexasSouthwestern Medical Center at Dallas (AJ Rush, principal investigator). Dr Perlis is supported by NIMH K23MH67060, a NARSAD Young Investigator Award, and a Bowman Family Foundation award. We thank Rutgers Cell and DNA Repository for extracting DNA and for providing samples. We appreciate the support of Forest Laboratories, Wyeth, Pfizer, GlaxoSmithKline, and Bristol-Myers Squibb for providing medications at no cost to the STAR ${ }^{\star} \mathrm{D}$ study. We also thank Stephen Wisniewski, $\mathrm{PhD}$, and Heather Eng for providing the clinical data. We thank the $S T A R^{\star} D$ research team, who conducted the clinical study and obtained the clinical data and the blood samples for these analyses. Finally, we thank the study participants without whom this study would not have been possible.

\section{DISCLOSURE OF FINANCIAL COMPETING INTEREST}

\section{Roy H Perlis, MD}

Research support: Eli Lilly \& Company, Elan/Eisai, National Institute of Mental Health, NARSAD, Bowman Family Foundation, American Philosophical Society.

Advisory/consulting: AstraZeneca, Bristol-Myers Squibb Company, Eli Lilly \& Company, Pfizer Inc.

Speaking: AstraZeneca, Bristol-Myers Squibb Company, Eli Lilly \& Company, GlaxoSmithKline, Pfizer Inc.

Equity holdings: none.

Royalty/patent, other income: none.

\section{Maurizio Fava, MD}

Research support: Abbott Laboratories, Alkermes, Aspect Medical Systems, AstraZeneca, Bristol-Myers Squibb Company, Cephalon, Eli Lilly \& Company, Forest
Pharmaceuticals Inc., GlaxoSmithKline, J\&J Pharmaceuticals, Lichtwer Pharma GmbH, Lorex Pharmaceuticals, Novartis, Organon Inc., PamLab, LLC, Pfizer Inc., Pharmavite, Roche, Sanofi/Synthelabo, Solvay Pharmaceuticals Inc., Wyeth-Ayerst Laboratories.

Advisory/consulting: Aspect Medical Systems, AstraZeneca, Bayer AG, Biovail Pharmaceuticals Inc., BrainCells Inc., Bristol-Myers Squibb Company, Cephalon, Compellis, Cypress Pharmaceuticals, Dov Pharmaceuticals, Eli Lilly \& Company, EPIX Pharmaceuticals, Fabre-Kramer Pharmaceuticals Inc., Forest Pharmaceuticals Inc., GlaxoSmithKline, Grunenthal GmBH, Janssen Pharmaceutica, Jazz Pharmaceuticals, J\&J Pharmaceuticals, Knoll Pharmaceutical Company, Lundbeck, MedAvante Inc., Neuronetics, Novartis, Nutrition 21, Organon Inc., PamLab, LLC, Pfizer Inc., PharmaStar, Pharmavite, Roche, Sanofi/Synthelabo, Sepracor, Solvay Pharmaceuticals Inc., Somaxon, Somerset Pharmaceuticals, Wyeth-Ayerst Laboratories.

Speaking: AstraZeneca, Boehringer-Ingelheim, BristolMyers Squibb Company, Cephalon, Eli Lilly \& Company, Forest Pharmaceuticals Inc., GlaxoSmithKline, Novartis, Organon Inc., Pfizer Inc., PharmaStar, Wyeth-Ayerst Laboratories.

Equity holdings: Compellis, MedAvante.

Royalty/patent, other income: none.

Madhukar H Trivedi, MD

Research support: Bristol-Myers Squibb Company; Cephalon Inc., Corcept Therapeutics Inc., Cyberonics Inc., Eli Lilly \& Company, Forest Pharmaceuticals, GlaxoSmithKline, Janssen Pharmaceutica, Merck, National Institute of Mental Health, National Alliance for Research in Schizophrenia and Depression, Novartis, Pfizer Inc., Predix Pharmaceuticals, Wyeth-Ayerst Laboratories.

Advisory/consulting: Abbott Laboratories Inc.; Akzo (Organon Pharmaceuticals Inc.); Bayer; Bristol-Myers Squibb Company; Cyberonics Inc.; Forest Pharmaceuticals; GlaxoSmithKline; Janssen Pharmaceutica Products, LP; Johnson \& Johnson PRD; Eli Lilly \& Company; Meade Johnson; Parke-Davis Pharmaceuticals Inc.; Pfizer Inc.; Pharmacia \& Upjohn; Sepracor; Solvay Pharmaceuticals Inc.; Wyeth-Ayerst Laboratories.

Speaking: Akzo (Organon Pharmaceuticals Inc.); BristolMyers Squibb Company; Cyberonics Inc.; Forest Pharmaceuticals; Janssen Pharmaceutica Products, LP; Eli Lilly \& Company; Pharmacia \& Upjohn; Solvay Pharmaceuticals Inc.; Wyeth-Ayerst Laboratories.

Equity holdings: none (exclude mutual funds/blinded trusts).

Royalty/patent, other income: none.

A John Rush, MD

Speaker's bureau: Cyberonics Inc., Forest Pharmaceuticals Inc., GlaxoSmithKline, and Eli Lilly \& Company.

Advisory boards/consulting: Advanced Neuromodulation Systems Inc., AstraZeneca, Best Practice Project Management Inc., Bristol-Myers Squibb Company, Cyberonics Inc., Eli Lilly \& Company, Forest Pharmaceuticals Inc., Gerson Lehman Group, GlaxoSmithKline, Healthcare Technology Systems, Jazz Pharmaceuticals, Magellan Health Services, Merck \& Company, Neuronetics, Ono Pharmaceuticals, Organon Pharmaceuticals Inc., PamLab, Personality Disorder Research Corp., Pfizer Inc., The Urban Institute, Wyeth-Ayerst Laboratories Inc. 
Research support: Robert Wood Johnson Foundation, National Institute of Mental Health, Stanley Medical Research Institute.

Royalties: Guilford Publications, Healthcare Technology Systems.

Stock: Pfizer Inc.

Jordan W Smoller, MD, ScD

Dr Smoller has received honoraria from Hoffman-La Roche Inc. and has served on an advisory board for Roche Diagnostics Corporation. He has received research funding from the National Institute of Mental Health and the National Alliance for Research in Schizophrenia and Depression.

The other authors have no financial competing interest to disclose.

\section{REFERENCES}

Buetow KH, Edmonson M, MacDonald R, Clifford R, Yip P, Kelley J et al (2001). High-throughput development and characterization of a genomewide collection of gene-based single nucleotide polymorphism markers by chip-based matrixassisted laser desorption/ionization time-of-flight mass spectrometry. Proc Natl Acad Sci USA 98: 581-584.

Crowley JJ, Brodkin ES, Blendy JA, Berrettini WH, Lucki I (2006). Pharmacogenomic evaluation of the antidepressant citalopram in the mouse tail suspension test. Neuropsychopharmacology 31: 2433-2442.

Crown WH, Finkelstein S, Berndt ER, Ling D, Poret AW, Rush AJ et al (2002). The impact of treatment-resistant depression on health care utilization and costs. J Clin Psychiatry 63: 963-971.

de Bakker PI, Yelensky R, Pe'er I, Gabriel SB, Daly MJ, Altshuler D (2005). Efficiency and power in genetic association studies. Nat Genet 37: 1217-1223.

Fava M (2003). Diagnosis and definition of treatment-resistant depression. Biol Psychiatry 53: 649-659.

Fava M, Davidson KG (1996). Definition and epidemiology of treatment-resistant depression. Psychiatr Clin North Am 19: 179-200.

Fava M, Rush AJ, Trivedi MH, Nierenberg AA, Thase ME, Sackeim HA et al (2003). Background and rationale for the sequenced treatment alternatives to relieve depression (STAR ${ }^{\star D}$ ) study. Psychiatr Clin North Am 26: 457-494, x.

Fink M, Duprat F, Lesage F, Reyes R, Romey G, Heurteaux C et al (1996). Cloning, functional expression and brain localization of a novel unconventional outward rectifier $\mathrm{K}+$ channel. EMBO J 15: 6854-6862.

Gordon JA, Hen R (2006). TREKing toward new antidepressants. Nat Neurosci 9: 1081-1083.

Hamilton M (1960). A rating scale for depression. J Neurol Neurosurg Psychiatry 23: 56-62.

Heurteaux C, Lucas G, Guy N, El Yacoubi M, Thümmler S, Peng XD et al (2006). Deletion of the background potassium channel TREK-1 results in a depression-resistant phenotype. Nat Neurosci 9: 1134-1141.

Honore E (2007). The neuronal background K2P channels: focus on TREK1. Nat Rev Neurosci 8: 251-261.

Kennard LE, Chumbley JR, Ranatunga KM, Armstrong SJ, Veale EL, Mathie A (2005). Inhibition of the human two-pore domain potassium channel, TREK-1, by fluoxetine and its metabolite norfluoxetine. Br J Pharmacol 144: 821-829.

Lavori PW, Rush AJ, Wisniewski SR, Alpert J, Fava M, Kupfer DJ et al (2001). Strengthening clinical effectiveness trials: equipoisestratified randomization. Biol Psychiatry 50: 792-801.

Lopes CM, Rohacs T, Czirjak G, Balla T, Enyedi P, Logothetis DE (2005). PIP2 hydrolysis underlies agonist-induced inhibition and regulates voltage gating of two-pore domain $\mathrm{K}+$ channels. J Physiol 564: 117-129.

Malhotra AK, Murphy Jr GM, Kennedy JL (2004). Pharmacogenetics of psychotropic drug response. Am J Psychiatry 161: 780-796.

McMahon FJ, Buervenich S, Charney D, Lipsky R, Rush AJ, Wilson AF et al (2006). Variation in the gene encoding the serotonin $2 \mathrm{~A}$ receptor is associated with outcome of antidepressant treatment. Am J Hum Genet 78: 804-814.

Murbartian J, Lei Q, Sando JJ, Bayliss DA (2005). Sequential phosphorylation mediates receptor- and kinase-induced inhibition of TREK-1 background potassium channels. J Biol Chem 280: 30175-30184.

Murphy Jr GM, Kremer C, Rodrigues HE, Schatzberg AF (2003). Pharmacogenetics of antidepressant medication intolerance. Am J Psychiatry 160: 1830-1835.

Neale BM, Sham PC (2004). The future of association studies: genebased analysis and replication. Am J Hum Genet 75: 353-362.

Ott J, Hoh J (2003). Set association analysis of SNP case-control and microarray data. J Comput Biol 10: 569-574.

Perlis RH, Purcell S, Fava M, Fagerness J, Rush AJ, Trivedi MH et al (2007). Association between treatment-emergent suicidal ideation with citalopram and polymorphisms near cyclic adenosine monophosphate response element binding protein in the STAR ${ }^{\star} \mathrm{D}$ study. Arch Gen Psychiatry 64: 689-697.

Porsolt RD, Bertin A, Jalfre M (1977). Behavioral despair in mice: a primary screening test for antidepressants. Arch Int Pharmacodyn Ther 229: 327-336.

Purcell S, Neale BM, Todd-Brown K, Thomas L, Ferreira MA, Bender D et al (2007). PLINK: a toolset for whole genome association and population-based linkage analyses. Am J Hum Genet 81: 559-575.

Rush AJ, Bernstein IH, Trivedi MH, Carmody TJ, Wisniewski S, Mundt JC et al (2006a). An evaluation of the quick inventory of depressive symptomatology and the Hamilton rating scale for depression: a sequenced treatment alternatives to relieve depression trial report. Biol Psychiatry 59: 493-501.

Rush AJ, Carmody T, Reimitz P (2000). The inventory of depressive symptomatology (IDS): clinician (IDS-C) and selfreport (IDS-SR) ratings of depressive symptoms. Int J Methods Psychiatr Res 9: 45-59.

Rush AJ, Fava M, Wisniewski SR, Lavori PW, Trivedi $\mathrm{MH}$, Sackeim HA et al (2004). Sequenced treatment alternatives to relieve depression $\left(\mathrm{STAR}^{\star} \mathrm{D}\right)$ : rationale and design. Control Clin Trials 25: 119-142.

Rush AJ, Gullion CM, Basco MR, Jarrett RB, Trivedi MH (1996). The inventory of depressive symptomatology (IDS): psychometric properties. Psychol Med 26: 477-486.

Rush AJ, Trivedi MH, Ibrahim HM, Carmody TJ, Arnow B, Klein DN et al (2003). The 16-item quick inventory of depressive symptomatology (QIDS), clinician rating (QIDS-C), and self-report (QIDS-SR): a psychometric evaluation in patients with chronic major depression. Biol Psychiatry 54: 573-583.

Rush AJ, Trivedi MH, Wisniewski SR, Nierenberg AA, Stewart JW, Warden D et al (2006b). Acute and longer-term outcomes in depressed outpatients requiring one or several treatment steps: a STAR ${ }^{\star D}$ report. Am J Psychiatry 163: 1905-1917.

Rush AJ, Trivedi MH, Wisniewski SR, Stewart JW, Nierenberg AA, Thase ME et al (2006c). Bupropion-SR, sertraline, or venlafaxine-XR after failure of SSRIs for depression. N Engl J Med 354: $1231-1242$

Santarelli L, Saxe M, Gross C, Surget A, Battaglia F, Dulawa S et al (2003). Requirement of hippocampal neurogenesis for the behavioral effects of antidepressants. Science 301: 805-809.

Schafer WR (1999). How do antidepressants work? Prospects for genetic analysis of drug mechanisms. Cell 98: 551-554. 
Serretti A, Cusin C, Rausch JL, Bondy B, Smeraldi E (2006). Pooling pharmacogenetic studies on the serotonin transporter: a mega-analysis. Psychiatry Res 145: 61-65.

Sklar P, Gabriel SB, McInnis MG, Bennett P, Lim YM, Tsan G et al (2002). Family-based association study of 76 candidate genes in bipolar disorder: BDNF is a potential risk locus. Brain-derived neutrophic factor. Mol Psychiatry 7: 579-593.

Souery D, Papakostas GI, Trivedi MH (2006). Treatment-resistant depression. J Clin Psychiatry 67(Suppl 6): 16-22.

Sullivan PF (2007). Spurious genetic associations. Biol Psychiatry 61: $1121-1126$.

Svenningsson P, Chergui K, Rachleff I, Flajolet M, Zhang X, El Yacoubi $M$ et al (2006). Alterations in 5-HT1B receptor function by p11 in depression-like states. Science 311: 77-80.

Talley EM, Solorzano G, Lei Q, Kim D, Bayliss DA (2001). CNS distribution of members of the two-pore-domain (KCNK) potassium channel family. J Neurosci 21: 7491-7505.

Tedlow J, Fava M, Uebelacker L, Nierenberg AA, Alpert JE, Rosenbaum J (1998). Outcome definitions and predictors in depression. Psychother Psychosom 67: 266-270.

Trivedi MH, Fava M, Wisniewski SR, Thase ME, Quitkin F, Warden D et al (2006a). Medication augmentation after the failure of SSRIs for depression. N Engl J Med 354: 1243-1252.
Trivedi MH, Rush AJ, Ibrahim HM, Carmody TJ, Biggs MM, Suppes $\mathrm{T}$ et al (2004). The inventory of depressive symptomatology, clinician rating (IDS-C) and self-report (IDS-SR), and the quick inventory of depressive symptomatology, clinician rating (QIDS-C) and self-report (QIDS-SR) in public sector patients with mood disorders: a psychometric evaluation. Psychol Med 34: 73-82.

Trivedi MH, Rush AJ, Wisniewski SR, Nierenberg AA, Warden D, Ritz L et al (2006b). Evaluation of outcomes with citalopram for depression using measurement-based care in $\mathrm{STAR}^{\star} \mathrm{D}$ : implications for clinical practice. Am J Psychiatry 163: $28-40$.

Tsankova NM, Berton O, Renthal W, Kumar A, Neve RL, Nestler EJ (2006). Sustained hippocampal chromatin regulation in a mouse model of depression and antidepressant action. Nat Neurosci 9: 519-525.

Walsh BT, Seidman SN, Sysko R, Gould M (2002). Placebo response in studies of major depression: variable, substantial, and growing. JAMA 287: 1840-1847.

Wisniewski SR, Fava M, Trivedi MH, Thase ME, Warden D, Niederehe $\mathrm{G}$ et al. Which second step treatments are acceptable to depressed outpatients and their clinicians? A STAR ${ }^{\star} \mathrm{D}$ report. Am J Psychiatry (in press).

Supplementary Information accompanies the paper on the Neuropsychopharmacology website (http://www.nature.com/npp) 